\title{
IDENTIFIKASI DAN PENETAPAN KADAR PENTOXYFILLIN DALAM SEDIAAN TABLET SECARA SPEKTROFOTOMETRI FOURIER TRANSFORM INFRARED (FT-IR) DAN SPEKTROFOTOMETRI UV-VISIBEL
}

\section{IDENTIFICATION AND DETERMINATION OF PENTOXYFILLIN LEVELS IN TABLET PREPARATIONS BY FOURIER TRANSFORM INFRARED SPECTROPHOTOMETRY (FT-IR) AND UV-VISIBLE SPECTROPHOTOMETRY}

\author{
Faisal Ismail $^{1 *}$, Dilla Kanitha ${ }^{1}$ \\ ${ }^{1}$ Poltekes Kemenkes Jakarta II \\ *Corresponding Author Email : faisalismail212@gmail.com \\ DOI: http://dx.doi.org/10.47653/farm.v7i2.523
}

\begin{abstract}
ABSTRAK
Aterosklerosis memiliki peranan penting dalam penyakit jantung koroner dengan ditandai dengan adanya penumpukan terus-menerus plak di dinding pembuluh darah arteri koroner. Pentoxyfillin merupakan turunan metilxantin. Pada pemakaian obat dalam pentoxyfillin digunakan untuk aterosklerosis atau diabetes mellitus dengan indikasi meredakan sakit. Tujuan dari penelitian ini adalah mengidentifikasi dan metetapkan kadar dari pentoxyfillin. Dalam penelitian ini dilakukan pengukuran menggunakan spektrofotometri Fourier Transform Infra Red (FT-IR) dengan pembuatan pellet $\mathrm{KBr}$. Pembuatan pellet dibuat dengan menggunakan tekanan menggunakan alat hand press dengan bobot tekanan 8 ton. Dilanjutkan dengan penetapan kadar pentoxyfillin dalam sediaan tablet menggunakan metode spektrofotometri UV-Visibel pada panjang gelombang maksimum $\pm 274 \mathrm{~nm}$, dengan menggunakan methanol sebagai blangko. Berdasarkan pengujian yang telah dilakukan didapat hasil identifikasi berupa bilangan gelombang pada daerah $3000-2750 \mathrm{~cm}^{-1}$ yang menunjukkan gugus $-\mathrm{CH}$, -CO, amida - $\mathrm{CO}$ rengang, pada bilangan gelombang $1750-1500 \mathrm{~cm}^{-1}$ yang menunjukkan gugus $-\mathrm{CH}$ dan pada bilangan gelombang $750-800 \mathrm{~cm}^{-1}$ menunjukkan gugus $-\mathrm{CH}_{2}$, dan hasil kadar $407 \mathrm{mg}$. Dari hasil pengujian kadar tablet pentoxyfillin dapat disimpulkan bahwa sediaan tablet pentoxyfillin memenuhi persyaratan Standar Internal.
\end{abstract}

Kata Kunci: Pentoxyfillin Tablet, Spektrofotmetri FT-IR, Spektrofotmetri UV-Visibel

\begin{abstract}
Atherosclerosis has an important role in coronary heart disease characterized by a continuous buildup of plaque in the walls of coronary arteries. Pentoxyfillin is a methylxanthine derivative. The use of drugs in pentoxyfillin is used for atherosclerosis or diabetes mellitus with an indication of pain relief. The purpose of this study is to identify and determine levels of pentoxyfillin. In this study measurements were taken using Fourier Transform Infra Red (FT-IR) spectrophotometric by making $\mathrm{KBr}$ pellets. Pellet making is made using pressure using a hand press with a weight of 8 tons. Followed by the determination of levels of pentoxyfillin in tablet preparations using the UV-Visible spectrophotometric method at a maximum wavelength of $\pm 274 \mathrm{~nm}$, using methanol as a blank. Based on the tests that have been carried out, the identification results obtained in the form of number of waves in the area of 3000-2750 $\mathrm{cm}^{-1}$ which shows the group $-\mathrm{CH},-\mathrm{CO}$, amide -CO stretched, on the number of waves of $1750-1500 \mathrm{~cm}^{-1}$ which shows the $-\mathrm{CH}$ group and at $750-800 \mathrm{~cm}^{-1}$ indicates the $-\mathrm{CH}_{2}$ group, and the resulting level of $407 \mathrm{mg}$. From the results of testing the levels of pentoxyfillin tablets it can be concluded that the preparations of pentoxyfillin tablets meet the requirements of Internal Standards.
\end{abstract}

Keywords: Pentoxyfillin Tablets, FT-IR Spectrophotometry, UV-Visible Spectrophotometry

\section{PENDAHULUAN}

Aterosklerosis memiliki peranan penting dalam penyakit jantung koroner dengan

ditandai dengan adanya penumpukan terus menerus plak di dinding pembuluh darah arteri 
koroner. Apabila pada permukaan arteri koroner terbentuk bekuan darah di bagian atas plak, dan menimbulkan sumbatan pada arteri koroner tersebut, maka aliran darah yang kaya akan oksigen yang dibutuhkan oleh otot jantung akan terhambat. Hal ini menyebabkan otot jantung tersebut akan mengalami 'kelaparan' (iskemia) dan kerusakan berat bahkan kematian sel otot jantung (infark miokard) atau disebut serangan jantung (Kementerian Kesehatan RI, 2011).

Faktor risiko penyakit jantung dan pembuluh darah meliputi faktor risiko yang tidak dapat dimodifikasi, seperti riwayat keluarga, umur, jenis kelamin, sedangkan faktor risiko yang dimodifikasi, seperti: hipertensi, merorok, diabetes mellitus, dislipidemia (metabolisme lemak yang abnormal), obesitas umum dan obesitas khusus, kurang aktivitas fisik, pola makan, konsumsi minuman beralkohol, dan stress (Kementerian Kesehatan RI, 2011).

Pentoxyfillin adalah turunan metilxantin (Utami, 2012). Telah disarankan bahwa pentoxyfillin dapat digunakan pada penyakit yang mempengaruhi aliran darah retina, seperti retinopati diabetik atau degenerasi macula (Unni, 2009). Namun, pada pemakaian obat dalam pentoxyfillin digunakan untuk aterosklerosis atau diabetes mellitus dengan indikasi meredakan sakit. Karena pentoxifyllin adalah turunan metil-xantin dengan berbagai efek anti inflamasi. Meskipun, penggunaan dan keefektifan pentoxifylline untuk berbagai kondisi dermatologis telah dibuktikan dalam berbagai penelitian selama periode yang lama, namun Badan Pengawas Obat dan Makanan Amerika Serikat (FDA) telah menyetujui penggunaannya hanya untuk klaudikasio intermiten (Hassan, 2014). Metilxantin (teofilin, garamnya yang mudah larut dan turunannya) akan merelaksasi secara langsung otot polos bronki dan pembuluh darah pulmonal, merangsang sistem syaraf pusat (SSP), menginduksi diuresis, meningkatkan sekresi asam lambung, menurunkan tekanan sfinkter esofageal bawah dan menghambat kontraksi uterus. Teofilin juga merupakan stimulan pusat pernafasan. Aminofilin mempunyai efek kuat pada kontraktilitas diafragma pada orang sehat dan dengan demikian mampu menurunkan kelelahan serta memperbaiki kontraktilitas pada pasien dengan penyakit obstruksi saluran pernapasan kronik (Departemen Kesehatan, 2007).
Obat golongan metilxantin bekerja dengan menghambat enzim fosfodiesterase sehingga mencegah penguraian siklik adenosina monofosfat (AMP), sehingga kadar siklik adenosina monofosfat (AMP) intrasel meningkat. Hal ini akan merelaksasi otot polos bronkus dan mencegah pelepasan mediator alergi seperti histamin dan leukotrien dari sel mast. Selain itu metilxantin juga mengantagonis bronkokontriksi yang disebabkan oleh prostaglandin dan memblok reseptor adenosine (Ikawati, 2006). Obat golongan metilxantin memiliki efek pada sistem syaraf pusat dan stimulasi jantung. Mereka meningkatkan curah jantung dan menurunkan tekanan pembuluh vena sehingga menimbulkan berbagai reaksi samping yang tidak diinginkan.<smiles>CC(=O)CCCCn1c(=O)c2c(ncn2C)n(C)c1=O</smiles>

Gambar 1. Rumus Bangun Pentoxyfillin (Direktorat Jenderal Pengawasan Obat dan Makanan, 2014)

Tablet merupakan bentuk sediaan padat yang terdiri dari satu atau lebih bahan obat yang dibuat dengan pemadatan. Tablet juga memiliki perbedaan dalam ukuran, bentuk, berat, kekerasan ataupun ketebalannya (Gloria dan Elisa, 2018). Pengertian obat ialah semua zat baik kimiawi, hewani maupun nabati, yang dalam dosis layak dapat menyembuhkan, meringankan atau mencegah penyakit berikut gejala-gejalanya (Sulanjani dkk, 2013).

Berdasarkan gugus fungsi suatu senyawa organik yang dimiliki pentoxyfillin, maka identifikasi tablet pentoxyfillin dapat dilakukan dengan metode spektrofotometri fourier transform infrared (FT-IR). Spektrofotometri fourier transform infrared (FT-IR) yang merupakan salah satu metode pengukuran untuk mendeteksi struktur molekul senyawa melalui identifikasi gugus fungsi penyusun senyawa. Sedangkan, gugus kromofor dan auksokrom yang dimiliki pentoxyfillin, akan di tetapan kadar pentoxyfillin tablet dilakukan dengan metode spektrofotometri UV-Vis. Sinar ultraviolet berada pada panjang gelombang 200-400 nm sedangkan sinar tampak berada 
pada panjang gelombang 400-800 nm (Dachriyanus, 2017).

Pengujian bertujuan untuk melihat identifikasi pentoxifylline dalam sediaan tablet secara spektrofotometri fourier transform infrared (FT-IR) dan menentukan penetapan kadar pentoxifyllin dalam sediaan tablet secara spektrofotometri ultraviolet. Spektroskopi Fourier Transform Infrared (FT-IR) yang merupakan salah satu metode pengukuran untuk mendeteksi struktur molekul senyawa melalui identifikasi gugus fungsi penyusun senyawa (Sulistyani, 2017). Spektrum yang dihasilkan berupa grafik yang menunjukkan persentase transmitan yang bervariasi pada setiap frekuensi radiasi inframerah.

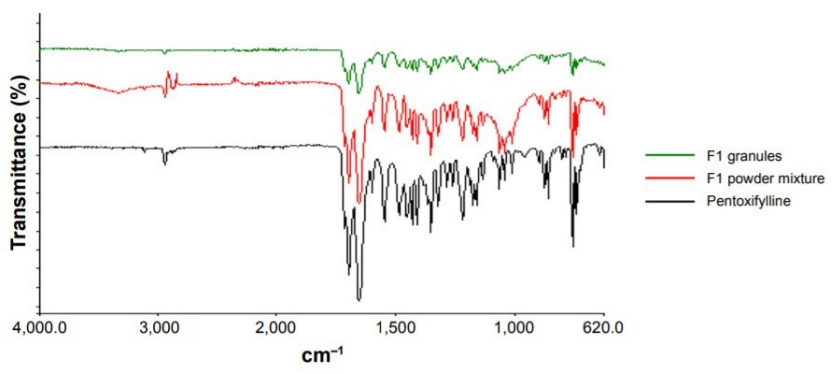

Gambar 2. Spektrum Inframerah Pentoxyfillin (Rahim dkk, 2015)

\section{METODE PENELITIAN}

\section{Alat}

Alat-alat yang digunakan pada penelitian ini adalah Spektrofotometer UV1800 shimadzu, Spektrofotometri Fourier Transform Infrared (FT-IR) shimadzu, timbangan analitik Satorius,MC1 Analytic AC 210 S, ultrasonik Transsonic TP 690,Elma, alat Sentrifugasi Hettich, oven, hand Press SSP-10A, dan alat Gelas.

\section{Bahan}

Bahan yang digunakan pada penelitian ini adalah Sampel Tablet "X", baku Pembanding Kerja Pentoxyfillin, methanol p.a (Merck), dichloromethane (Merck), natrium Sulfat (NaSo 4$)$ anhydrous(Merck), dietil Eter (Merck), kalium Bromida ( $\mathrm{KBr}$ ) (Merck), purified water, methanol p.a (Merck), dichloromethane (Merck), dietil Eter (Merck), dan purified water.

\section{Metode \\ Prosedur Identifikasi Pentoxyfyllin secara Fourier Transform Infrared (FT-IR)}

Ditimbang $\pm 200 \mathrm{mg}$ massa serbuk tablet contoh, masukkan kedalam labu sentrifuga, ditambahkan $10 \mathrm{~mL}$ methanol dan kocok selama 5 menit lalu disentifuga, dituangkan larutan jernih ke dalam cawan penguap dan uapkan pada suhu $35^{\circ} \mathrm{C}$, larutkan residu yang tertinggal dengan $15 \mathrm{~mL}$ dicloromethane dan tuangkan ke dalam corong pisah yang berisi $10 \mathrm{~mL}$ purified water, dikocok selama 5 menit dan pisahkan lapisan organik dengan mengalirkan corong gelas wool yang diisi dengan $\mathrm{NaSO}_{4}$ anhydrous ke dalam gelas kimia, diuapkan lapisan organik hingga kering pada suhu $35^{\circ} \mathrm{C}$, dilarutkan residu dengan $8-10$ $\mathrm{mL}$ eter dan dinginkan dalam ice bath, disaring dan kumpulkan presipitat lalu dicuci dengan 2 $\mathrm{mL}$ eter dingin, diuapkan dietil eter yang masih menempel pada prespitat sampai kering, dibuatkan pellet $\mathrm{KBr}$ dan periksa spektrumnya dan bandingkan dengan standar.

\section{Prosedur Penetapan Kadar Pentoxyfillin Secara Spektrofotometri UV-Vis Larutan Pembanding}

Ditimbang $40 \quad \mathrm{mg} \quad$ Pentoxyfillin pembanding, masukkan kedalam labu takar $100 \mathrm{~mL}$, ditambahkan methanol hingga tanda batas, kemudian larutkan, dipipet $5 \mathrm{~mL}$ larutan stok standar, masukkan ke dalam labu takar $100 \mathrm{~mL}$, ditambahkan methanol hingga tanda batas, aduk hingga homogen.

\section{Larutan Uji}

Dimasukkan 5 tablet contoh ke dalam labu takar $500 \mathrm{~mL}$. Tambahkan $350 \mathrm{~mL}$ methanol lalu kocok labu selama 2 menit, dibiarkan larutan dingin hingga suhu ruang, lalu tambahkan methanol hingga tanda batas, dipipet $10 \mathrm{~mL}$ larutan, masukkan ke dalam labu sentifuga, disentrifuga selama 5 menit pada $3000 \mathrm{rpm}$, dipipet $5 \mathrm{~mL}$ supernatant, masukkan ke dalam labu takar $100 \mathrm{~mL}$, ditambahkan methanol hingga tanda batas, kocok hingga homogen, dipipet $5 \mathrm{~mL}$ larutan di atas, masukkan ke dalam labu takar $50 \mathrm{~mL}$, ditambahkan methanol hingga tanda batas, kocok hingga homogen.

\section{Cara Penetapan}

Ukur masing - masing serapan larutan uji, pembanding dan keseragaman kadar pada $\lambda$ $274 \mathrm{~nm}$ menggunakan methanol sebagai blangko.

\section{Rumus Perhitungan Penetapan Kadar}

$$
\text { Pentoxyfillin }(\mathrm{mg} / \mathrm{tab})=\frac{\operatorname{ATx} \operatorname{CS} x 20000}{\mathrm{AS}}
$$

Dimana : 
AT : Absorbansi larutan uji

AS : Absorbansi larutan pembanding 20000 : Faktor pengenceran larutan uji

\section{Simpangan Baku Relatif}

$$
S D=\sqrt{\frac{\sum\left|X_{i}-\bar{x}\right|^{2}}{X-1}} \quad R S D=\frac{S D}{\bar{x}} \times 100 \%
$$

Dimana :

SD : Simpangan baku

RSD : Simpangan baku relatif

\section{Persyaratan}

Persyaratan pada penelitian ini yaitu identifikasi pentoxyfillin spektrum standar dengan spektrum uji sesuai dan persyaratan kadar pentoxyfillin dalam sediaan tablet adalah $380 \mathrm{mg} / \mathrm{tab}-420 \mathrm{mg} / \mathrm{tab}$ atau 99,0 \% - 105,0 $\%$.
CS: Konsentrasi larutan pembanding pentoxyfillin standar $(0.02 \mathrm{mg} / \mathrm{mL})$

HASIL DAN PEMBAHASAN

Identifikasi Pentoxyfyllin Secara Fourier Transform Infrared (FT-IR)

Tabel 1. Data Penimbangan Sampel

\begin{tabular}{ccc}
\hline No. & Keterangan & Bobot $(\mathbf{m g})$ \\
\hline 1 & Sampel & 200,3 \\
\hline
\end{tabular}

Tabel 2. Data Penimbangan Pellet

\begin{tabular}{ccc}
\hline No. & Keterangan & Bobot $(\mathbf{m g})$ \\
\hline 1 & $\mathrm{KBr}$ & 250,1 \\
2 & Sampel & 20
\end{tabular}

ФSHIMADZU

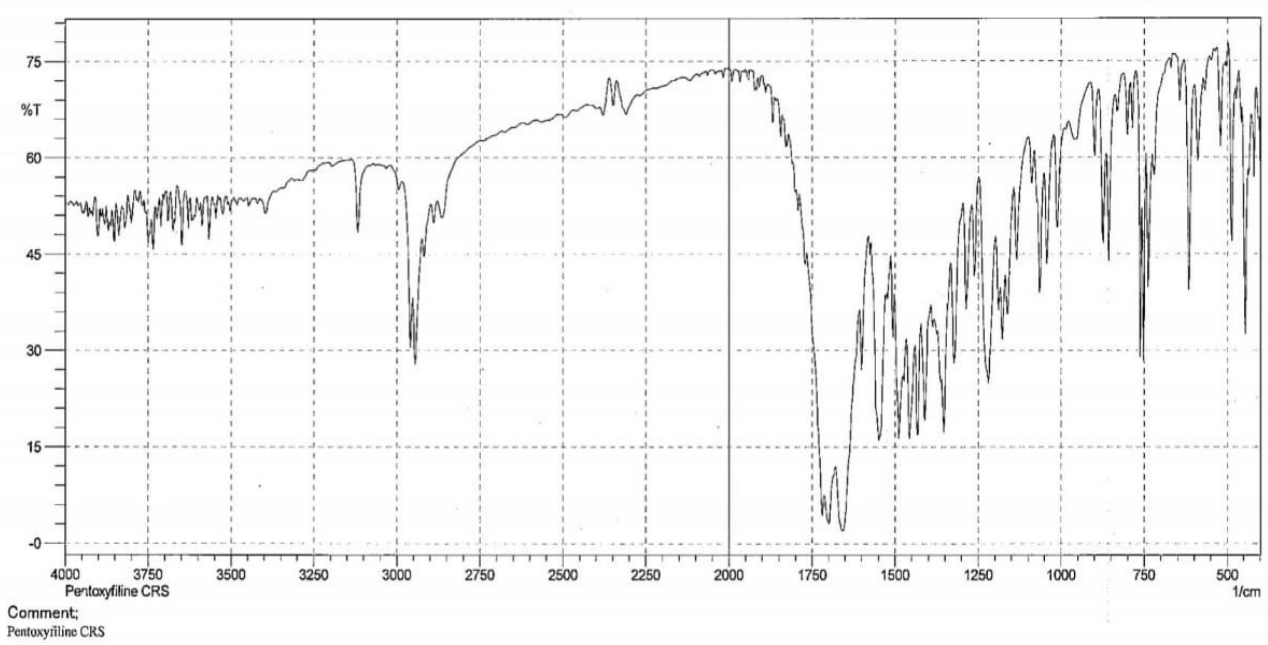

Gambar 3. Kromatogram Baku Pentoxyfillin

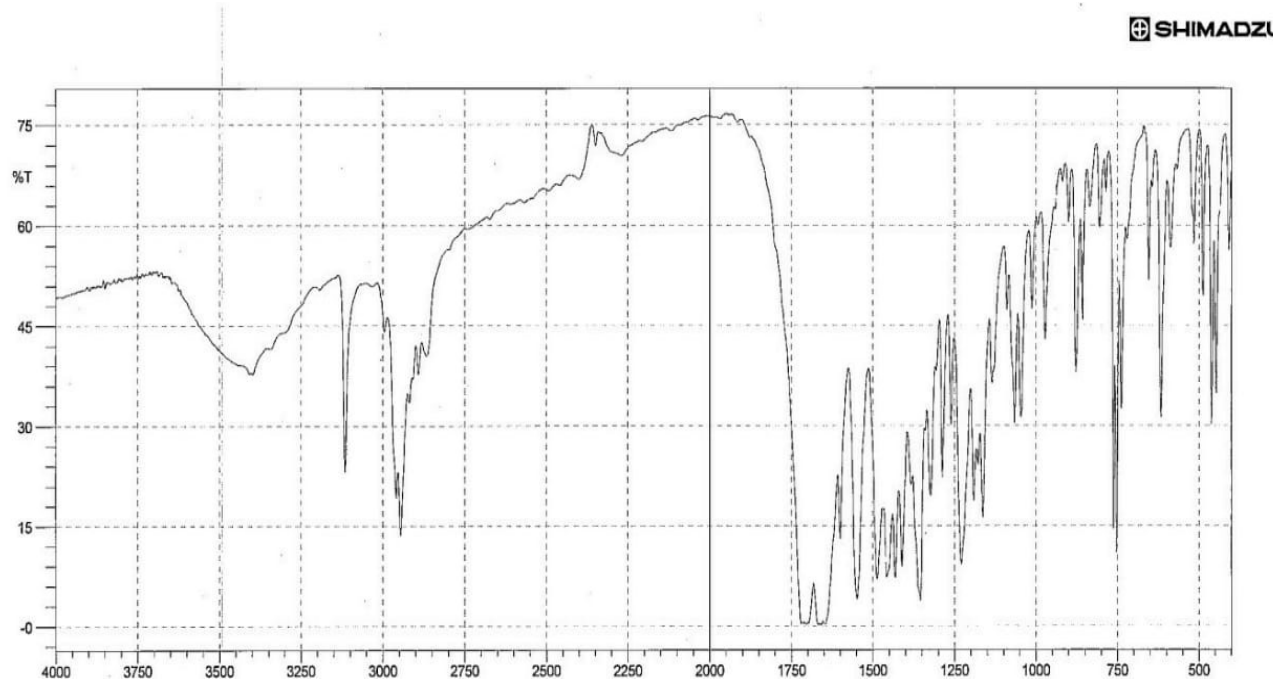

Gambar 4. Kromatogram Sampel Pentoxyfillin 


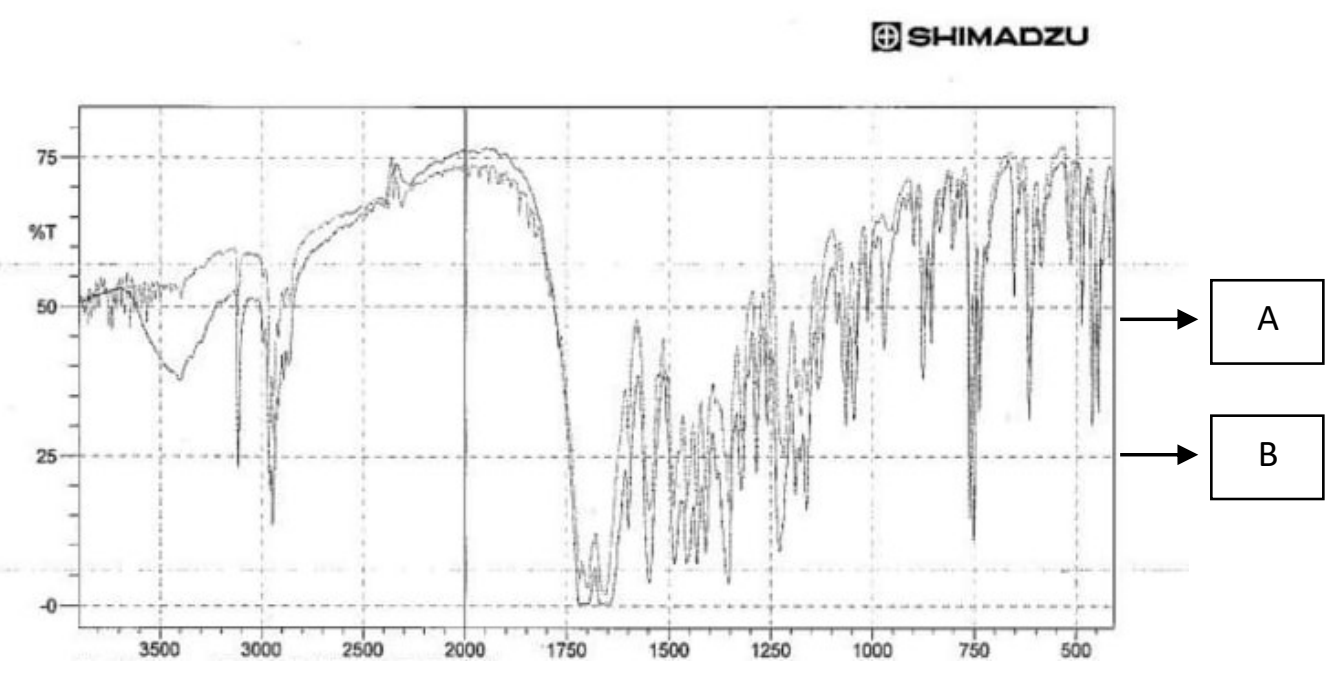

Gambar 8. Kromatogram Baku dan Sampel Pentoxyfillin

Keterangan :

A. Kromatogram Baku Pentoxyfillin

B. Kromatogram Sampel Pentoxyfillin

Tabel 3. Data Bilangan Gelombang Literatur (Rahim dkk, 2015)

\begin{tabular}{cc}
\hline Panjang Gelombang Literatur $\left(\mathbf{c m}^{-1}\right)$ & Perkiraan Gugus Fungsi \\
\hline 2,945 & \\
1,701 & $-\mathrm{CH},-\mathrm{CO}$, amida $-\mathrm{CO}$ rengang \\
1,658 & $-\mathrm{CH}$ \\
1,433 & $-\mathrm{CH}_{2}$ \\
752 & \\
\hline
\end{tabular}

Tabel 4. Data Bilangan Gelombang Baku Pentoxyfillin

\begin{tabular}{cc}
\hline $\begin{array}{c}\text { Panjang Gelombang } \\
\text { Baku Pentoxyfillin }\left(\mathbf{c m}^{-1}\right)\end{array}$ & Perkiraan Gugus Fungsi \\
\hline $3000-2,750$ & $-\mathrm{CH},-\mathrm{CO}$, amida $-\mathrm{CO}$ rengang \\
$1750-1495$ & $-\mathrm{CH}$ \\
$800-750$ & $-\mathrm{CH}_{2}$ \\
\hline
\end{tabular}

Tabel 5. Data Bilangan Gelombang Sampel Pentoxyfillin

\begin{tabular}{cc}
\hline $\begin{array}{c}\text { Panjang Gelombang } \\
\text { Sampel Pentoxyfillin }\left(\mathbf{c m}^{-1}\right)\end{array}$ & Perkiraan Gugus Fungsi \\
\hline $3000-2,750$ & $-\mathrm{CH},-\mathrm{CO}$, amida $-\mathrm{CO}$ rengang \\
$1750-1495$ & $-\mathrm{CH}$ \\
$800-750$ & $-\mathrm{CH}_{2}$ \\
\hline
\end{tabular}

Analisis spektrofotometri Fourier Transform Infrared (FT-IR) dilakukan untuk membuktikan bahwa sampel yang diuji memiliki gugus fungsional yang sama dengan baku, menunjukkan bahwa sampel benar mengandung senyawa pentoxyfillin. Kromatogram terjadi jika suatu frekuensi tertentu dari radiasi inframerah dilewatkan pada sampel suatu senyawa organik maka akan terjadi penyerapan frekuensi oleh senyawa tersebut. Detektor yang ditempatkan pada sisi lain dari senyawa akan mendeteksi frekuensi yang dilewatkan pada sampel yang tidak diserap oleh senyawa. Banyaknya frekuensi yang melewati senyawa (yang tidak diserap) akan diukur sebagai persen transmitan (Dachriyanus, 2017). Spektrum yang dihasilkan dari pembacaan spektrofotometer Fourier Transform Infrared (FT-IR) selanjutnya diinterpretasi meliputi bilangan gelombang dan persen transmitansinya untuk menentukan gugus 
fungsi yang terdapat pada sampel. Hasil dari pembacaan masing-masing variasi dibandingkan untuk melihat optimasi hasil pengukuran dengan variasi perbandingan komposisi pellet sampel- $\mathrm{KBr}$, ketebalan pellet sampel dan waktu pengepresan terhadap spektrum vibrasi yang dihasilkan menggunakan spektrofotometri Fourier Transform Infrared (FT-IR) sehingga didapatkan spektrum yang terbaik pada pengukuran vibrasi molekul menggunakan spektrofotometri Fourier Transform Infrared (FT-IR) (Sulistyani, 2017).

Pada tabel 4 dan 5 menunjukkan baku dan sampel memiliki persamaan dalam bilangan gelombang pada daerah $3000-2750$ $\mathrm{cm}^{-1}$ yang menunjukkan gugus $-\mathrm{CH},-\mathrm{CO}$, amida -CO rengang, pada bilangan gelombang $1750-1500 \mathrm{~cm}^{-1}$ yang menunjukkan gugus $\mathrm{CH}$ dan pada bilangan gelombang $750-800$ $\mathrm{cm}^{-1}$ menunjukkan gugus $-\mathrm{CH}_{2}$ yang sesuai sehingga identifikasi sampel memenuhi syarat (MS) sesuai dengan persyaratan yang menyatakan bahwa identifikasi pentoxyfillin spektrum standar dengan spektrum uji sesuai.

\section{Penetapan Kadar Pentoxyfillin secara Spektrofotometri UV-Vis}

Tabel 6. Data Absorbansi Baku dan Sampel (Terdapat pada lampiran 4)

\begin{tabular}{ccc}
\hline No. & Keterangan & Absorbansi \\
\hline 1 & Pembanding Pentoxyfillin & 0,683 \\
2 & Sampel 1 & 0,695 \\
3 & Sampel 2 & 0,694 \\
4 & Sampel 3 & 0,695 \\
5 & Blangko & 0,000 \\
\hline
\end{tabular}

Tabel 7. Data Simpangan Baku Relatif

\begin{tabular}{ccccc}
\hline No & Keterangan & Absorbansi & $\left(\mathbf{x}_{\mathbf{i}}-\overline{\mathbf{x}}\right)$ & $\left(\times_{i}-\overline{\mathbf{x}}\right)^{2}$ \\
\hline 1 & Pembanding Pentoxyfillin 1 & 0,684 & 0,001 & 0,000001 \\
2 & Pembanding Pentoxyfillin 2 & 0,682 & 0,001 & 0,000001 \\
3 & Pembanding Pentoxyfillin 3 & 0,683 & 0 & 0 \\
4 & Pembanding Pentoxyfillin 4 & 0,682 & 0,001 & 0,000001 \\
5 & Pembanding Pentoxyfillin 5 & 0,682 & 0,001 & 0,000001 \\
& $\Sigma$ & 3,414 & 0,004 & 0,000004 \\
& $\bar{x}$ & & & \\
& & 0,683 & 0,0008 & 0,0000008 \\
& & & &
\end{tabular}

Penggunaan metode spektrofotometri cahaya tampak dalam kadar pentoxyfillin karena dalam strukturnya terdapat ikatan rangkap terkonjungasi (kromofor) yang dapat dideteksi menggunakan spektrofotometer ultraviolet-cahaya tampak. Kromofor merupakan gugus tak jenuh (pada ikatan kovalen) yang bertanggung jawab terhadap terjadinya absorbsi elektronik (misalnya $\mathrm{C}=\mathrm{C}$, $\mathrm{C}=\mathrm{O}$, dan $\mathrm{NO}_{2}$ ). Auskrom adalah merupakan gugus jenuh dengan adanya elektron bebas (tidak terikat), dimana jika gugus ini bergabung dengan kromofor, akan mempengaruhi panjang gelombang dan intensitas absorban. Ikatan rangkap terkonjungasi yang terdapat dalam senyawa pentoxyfillin akan menyerap radiasi dari sinar ultraviolet atau sinar tampak yang digunakan dalam pengukuran (Dachriyanus, 2017).

Panjang gelombang maksimum $274 \mathrm{~nm}$ dipilih karena pada panjang gelombang tersebut absorbansi sinar monokromatik yang dihasilkan dari lampu deuterium memiliki nilai absorbs yang besar ditandai dengan tingginya puncak serapan dari pentoxyfillin yang terkandung dalam sampel dan baku. Selain itu, 
letak serapan maksimum dapat berbeda jika digunakan alat yang berbeda, maka sebaiknya pengukuran dilakukan pada panjang gelombang serapan maksimum yang diperoleh dengan alat yang digunakan dengan syarat toleransi panjang gelombang serapan maksimum yang diperoleh dengan alat digunakan dengan syarat toleransi panjang gelombang yang diperoleh adalah $\pm 1 \mathrm{~nm}$ untuk rentang ultraviolet dan $\pm 3 \mathrm{~nm}$ untuk rentang visibel (Council of Europe, 2005).

Berdasarkan pengujian kadar Pentoxyfillin dalam sediaan tablet secara Spektrofotometri UV-Vis diperoleh kadar sebesar $407 \mathrm{mg}$ atau $101,75 \%$ terhadap etiket dengan simpangan baku relatif sebesar $0,00014 \%$ sehingga dapat disimpulkan bahwa kadar sampel memenuhi syarat (MS) sesuai dengan persyaratan Internal Standar PT. Aventis Pharma yaitu 380 $\mathrm{mg} / \mathrm{tab}-420 \mathrm{mg} / \mathrm{tab}$ atau $95 \%-105 \%$.

\section{KESIMPULAN}

Berdasarkan pengujian identifikasi Pentoxyfillin dalam sedian tablet secara Spektrofotometri Fourier Transform Infrared (FT-IR) diperoleh spektrum standar dengan spektrum uji sesusai dengan hasil pengujian kadar Pentoxyfillin dalam sediaan tablet secara Spektrofotometri UV-Vis diperoleh kadar sebesar $407 \mathrm{mg}$ atau 101,75\% terhadap etiket dengan simpangan baku relatif sebesar $0,00014 \%$.

\section{DAFTAR PUSTAKA}

Council of Europe. 2005. European Pharmacopoeia 5th Ed. Test.

Dachriyanus D. 2017. Analisis Struktur Senyawa Organik Secara Spektroskopi. Analisis Struktur Senyawa Organik Secara Spektroskopi. Sumatera Barat: Lembaga Pengembangan Teknologi Informasi dan Komunikasi (LPTIK).

Departemen Kesehatan. 2007. Pharmaceutical Care. Jakarta. Departemen Kesehatan Republik Indonesia.

Direktorat Jenderal Pengawasan Obat dan Makanan. 2014. Farmakope Indonesia Edisi V. Direktorat Jenderal Pengawasan Obat dan Makanan.

Gloria M, Elisa Y. 2018. Teknologi Sediaan Solid. Pertama. Jakarta: Kementerian Kesehatan Republik Indonesia. 287 p.

Hassan I, Dorjay K, Anwar P. 2014. Pentoxifylline And Its Applications In
Dermatology. Indian Dermatol Online J. 5(4):510.

Ikawati, Zullies. 2006. Pengantar Farmakologi Molekuler Target Aksi Obat dan Mekanisme Molekulernya. Yogyakarta: Gajah Mada Univeity Press.

Ikhsanuddin M. 2017. Penentuan Konsentrasi Optimum Selulosa Ampas Tebu (Baggase) Dalam Pembuatan Film Bioplastik. Skripsi.

Kementerian Kesehatan RI. 2011. Pedoman Pengendalian Faktor Risiko Penyakit Jantung Dan Pembuluh Darah. Jakarta: Menteri Kesehatan. p. 7-8.

Nazar, Muhammad. 2018. Spektroskopi Molekul. Aceh: Syiah Kuala University Presss. 70 p.

Permanasari A., Zulkiyah, Asep, S., Siswaningsih, W. 2016. Kimia Analitik Instrumen. Pertama. Tangerang Selatan: Universitas tebuka. $411 \mathrm{p}$.

Rahim SA., Carter PA., Elkordy AA. 2015. Design And Evaluation Of Effervescent Floating Tablets Based On Hydroxyethyl Cellulose And Sodium Alginate Using Pentoxifylline As A Model Drug. 9(April):1843-57.

Sulanjani IAN, Nila A, Andini MDWI, Halim M. 2013. Dasar-Dasar Farmakologi 1. Pertama. Nila A, editor. Tim.

Sulistyani M. dan Nuril, Huda. 2017. Optimasi Pengukuran Spektrum Vibrasi Sampel Protein Menggunakan Spektrofotometer Fourier Transform Infrared (FT-IR). 6(2).

Suseno JE, Firdausi KS. 2008. Rancang Bangun Spektroskopi FTIR (Fourier Transform Infrared) untuk Penentuan Kualitas Susu Sapi. Berk Fis. 11(1):2328-28.

Unni LK, Womack C, Hannant ME, Becker RE. 2009. Pharmacokinetics And Pharmacodynamics Of Metrifonate In Humans. Magnusson M, editor. Vol. 16, Methods and Findings in Experimental and Clinical Pharmacology. Sweden: Lund University. 285-289 p.

Utami. 2012. Preparasi Dan Karakterisasi Beads Kalsium-Alginat Pentoksifillin Preparasi Dan Karakterisasi Beads Kalsium-Alginat Pentoksifillin Dengan Metode Gelasi Ion. 